\title{
Selectivity of the Formation of the Ring-Closed Products and Methylcyclohexenes in the Dehydrogenation of Methylcyclohexane to Toluene
}

\author{
Muhammad R. Usman, ${ }^{1,2}$ David L. Cresswell, ${ }^{1}$ and Arthur A. Garforth ${ }^{1}$ \\ ${ }^{1}$ School of Chemical Engineering and Analytical Science, The University of Manchester, Manchester M60 1QD, UK \\ ${ }^{2}$ Institute of Chemical Engineering and Technology, University of the Punjab, New Campus, Lahore 54590, Pakistan \\ Correspondence should be addressed to Muhammad R. Usman, mrusman.icet@pu.edu.pk
}

Received 4 May 2012; Accepted 28 May 2012

Academic Editors: M. Assael and S. Wang

Copyright (C) 2012 Muhammad R. Usman et al. This is an open access article distributed under the Creative Commons Attribution License, which permits unrestricted use, distribution, and reproduction in any medium, provided the original work is properly cited.

\begin{abstract}
In our previous publication (Usman et al., 2011), the by-products formation during the dehydrogenation of methylcyclohexane over $1.0 \mathrm{wt} \% \mathrm{Pt} / \gamma-\mathrm{Al}_{2} \mathrm{O}_{3}$ was studied under wide range of operating conditions. The formation and yield patterns of benzene, cyclohexane, and isomers of xylene were studied. In the present contribution, the formation and yield patterns of the ring-closed products (sum of ethylcyclopentane and dimethylcyclopentanes) and methylcyclohexenes are studied. The yields of both of the ring-closed products (RCPs) and methylcyclohexenes (MCHes) were observed to increase with an increase in pressure. However, the effect of hydrogen concentration was found affecting differently at the low and at the high pressures. The yield patterns of methylcyclohexenes suggested methylcyclohexenes as the reaction intermediate in the formation of toluene.
\end{abstract}

\section{Introduction}

The dehydrogenation of methylcyclohexane $(\mathrm{MCH})$ is an important model reaction in the reforming of naphtha [1]. Also, the dehydrogenation of $\mathrm{MCH}$ is an essential reaction in the MTH (methylcyclohexane-toluene-hydrogen) system for the safe and economical storage and utilization of hydrogen. For hydrogen storage applications (the MTH-system), the $\mathrm{Pt} / \mathrm{Al}_{2} \mathrm{O}_{3}$ catalyst is the recommended catalyst as it is highly active, selective towards toluene, and a stable catalyst $[2,3]$. In our previous publication [4], we discussed the formation of by-products in the dehydrogenation of methylcyclohexane over $1.0 \mathrm{wt} \% \mathrm{Pt} / \gamma-\mathrm{Al}_{2} \mathrm{O}_{3}$. It was observed that benzene, cyclohexane, and the ring-closed products (sum of ethylcyclopentane and dimethylcyclopentanes) generally had the highest yields and therefore recognized as the major byproducts. Isomers of xylene, methylcyclohexenes, dimethylbiphenyls, n-heptane, and 3-methylhexane were found as the minor by-products. The rest of the by-products ( $\mathrm{n}$ pentane, n-hexane, methylcyclopentane, cycloheptane, 1ethyl-2-methylcyclopentane, methylnaphthalene, diphenylmethane, methylbiphenyl, anthracene, and methylfluorenes) were present only in traces. The discussion was around the formation of two major by-products that are benzene and cyclohexane together with a minor product, the isomers of xylene. Xylenes were chosen for the study because the formation of xylenes is closely related to the formation of benzene and cyclohexane.

The present contribution is an extension of the abovementioned previous work [4]. In the present work, the formations of the remaining major byproduct, the ring-closed products (RCPs), and one important minor byproduct, namely, methylcyclohexenes (MCHes), are discussed. The by-product $\mathrm{MCHes}$ are chosen because they are considered as the reaction intermediate in the dehydrogenation of methylcyclohexane. The effect of pressure and feed composition on the yields together with the possible mechanisms of the formations of RCPs and MCHes is discussed. Throughout the following discussion, the term yield is percent molar yield as defined in the following:

$$
\text { Yield }=\frac{\text { moles of the given by-product }}{\text { moles of the } \mathrm{MCH} \text { fed }} \times 100
$$


TABLE 1: Groups formation for the experimental kinetic data obtained for the dehydrogenation of $\mathrm{MCH}$ over $1.0 \mathrm{wt} \% \mathrm{Pt} / \gamma-\mathrm{Al}_{2} \mathrm{O}_{3}[4]$.

\begin{tabular}{|c|c|c|c|c|c|c|}
\hline \multirow{2}{*}{ Group } & \multicolumn{3}{|c|}{ Feed composition } & \multirow{2}{*}{$T_{w}(\mathrm{~K})$} & \multirow{2}{*}{$p$ (bar) } & \multirow{2}{*}{$W / F_{A 0} \times 10^{-4} \mathrm{~s} \cdot \mathrm{g}$-cat- $/ \mathrm{mol}$} \\
\hline & $y_{A 0}$ & $y_{C 0}$ & $y_{I 0}$ & & & \\
\hline 11 & 0.106 & 0.893 & 0.001 & $614.2,634.2,653.2$ & 1.013 & $3.11,6.22,12.44$ \\
\hline 21 & 0.485 & 0.511 & 0.005 & $614.2,634.2,653.2$ & 1.013 & $3.11,6.22,12.44$ \\
\hline 31 & 0.990 & 0 & 0.010 & $614.2,634.2,653.2$ & 1.013 & $3.11,6.22,12.44$ \\
\hline 41 & 0.485 & 0 & 0.515 & $614.2,634.2,653.2$ & 1.013 & $3.11,6.22,12.44$ \\
\hline 15 & 0.106 & 0.893 & 0.001 & $614.2,634.2,653.2$ & 5.0 & $3.11,6.22,12.44$ \\
\hline 25 & 0.485 & 0.511 & 0.005 & $614.2,634.2,653.2$ & 5.0 & $3.11,6.22,12.44$ \\
\hline 45 & 0.485 & 0 & 0.515 & $614.2,634.2,653.2$ & 5.0 & $3.11,6.22,12.44$ \\
\hline 19 & 0.106 & 0.893 & 0.001 & $614.2,634.2,653.2$ & 9.0 & $3.11,6.22,12.44$ \\
\hline 29 & 0.485 & 0.511 & 0.005 & $614.2,634.2,653.2$ & 9.0 & $3.11,6.22,12.44$ \\
\hline 49 & 0.485 & 0 & 0.515 & $614.2,634.2,653.2$ & 9.0 & $3.11,6.22,12.44$ \\
\hline
\end{tabular}

\section{Experimental}

The dehydrogenation experiments were carried out in a fixed bed catalytic reactor with an internal diameter of $1.02 \mathrm{~cm}$. $1.0 \mathrm{wt} \% \mathrm{Pt} / \gamma-\mathrm{Al}_{2} \mathrm{O}_{3}$ was prepared by wet impregnation using chloroplatinic acid as the Pt precursor. The $\gamma-\mathrm{Al}_{2} \mathrm{O}_{3}$ support from Alfa-Aesar had a Brunauer-Emmett-Teller (BET) surface of $208 \mathrm{~m}^{2} / \mathrm{g}$ and pore volume of $0.58 \mathrm{~cm}^{3} / \mathrm{g}$. The experimental operating conditions are shown in Table 1, and these are collected in groups according to the operating pressure and feed composition to facilitate in interpreting the experimental results. The product samples of the dehydrogenation reaction, for byproducts analysis, were first subjected to qualitative analyses in a gas chromatographmass spectrometer (GC-MS) and then quantified in a gas chromatograph-flame ionization detector (GC-FID) system. Figure 1 shows a typical GC-MS response showing various by-products formed during the dehydrogenation of methylcyclohexane.

The detail of the experimental setup, catalyst preparation, and product analysis may be found in Usman et al. [5].

\section{Results and Discussion}

\subsection{Ring-Closed Products (RCPs)}

3.1.1. Reaction Mechanisms for the Formation of RCPs. Ethylcyclopentane (ECP) and dimethylcyclopentanes (DMCPs) are the two ring-closed by-products observed in the dehydrogenated products. The in-house developed $1.0 \mathrm{wt} \%$ $\mathrm{Pt} / \gamma-\mathrm{Al}_{2} \mathrm{O}_{3}$ catalyst, over which the dehydrogenation reaction is studied, is a bifunctional catalyst where the Pt metal takes on the function of hydrogenation-dehydrogenation while the alumina support provides with the acidic function. The presence of the acidity in the support used in the present study was confirmed by Alhumaidan [2] using $\mathrm{NH}_{3}$ TPD (temperature-programmed desorption). The measured acidity of $\gamma-\mathrm{Al}_{2} \mathrm{O}_{3}$ was $1.61 \times 10^{19}$ acid sites/g [2]. As chloroplatinic acid is used as a $\mathrm{Pt}$ precursor and $\mathrm{HCl}$ is employed to provide the right $\mathrm{pH}$ environment in the preparation of the catalyst, a little more acidity is expected due to chloride ions.
The formation of ECP and DMCPs is the result of isomerization reactions and requires the acidic function of the catalyst. The following two reaction mechanisms may be proposed for the formation of these by-products.

In the first mechanism, as shown in Figure 2(a), $\mathrm{MCH}$ first dehydrogenates to methylcyclohexene on the Pt sites and the partially dehydrogenated methylcyclohexane then isomerizes on acid sites to dimethylcyclopentenes (DMCPes) and ethylcyclopentene (ECPe). The DMCPes and ECPe exploit the metallic function of the bifunctional catalyst and hydrogenate to DMCPs and ECP, respectively, or dehydrogenate further to produce cyclopentadienes [6]. In our knowledge, for a bifunctional $\mathrm{Pt} / \alpha-\mathrm{Al}_{2} \mathrm{O}_{3}$ catalyst, this mechanism for the $\mathrm{MCH}$ dehydrogenation is reported by Tsakiris [6], and it is based on the suggestions of Sinfelt and Rohrer [7] and the mechanism proposed by Haensel et al. [8] for the formation of methylcyclopentene from cyclohexene.

In an alternate mechanism, as shown in Figure 2(b), $\mathrm{MCH}$ isomerizes on the acid support to form ECP and DMCPs. Under favorable thermodynamic conditions, ECP and DMCPs first dehydrogenate to form DECPe and DMCPes, respectively, which successively dehydrogenate to form cyclopentadienes.

The cyclopentadienes formed in both the Mechanism-I and Mechanism-II are highly unstable and readily polymerize to polycyclics (coke), as proposed by Myers et al. [9]. It is worthwhile mentioning here that aromatic compounds and especially partially dehydrogenated naphthenic compounds formed during the dehydrogenation of $\mathrm{MCH}$ are the potential precursors to coke formation and undergo polyaromatic and polycondensation reactions to form coke on the catalyst surface. For the present study, the presence of biphenyls, naphthalenes, diphenylmethane, fluorenes, and anthracene in the dehydrogenation products supports the above argument.

3.1.2. Yield Patterns of RCPs. Generally, the yield of RCPs increases with an increase in the $\mathrm{MCH}$ conversion, $X$. At atmospheric pressure, as shown in Figure 3(a), the yield of RCPs first increases with the $\mathrm{MCH}$ conversion and then virtually leveled off with the horizontal. Similar behavior was observed by Al-Sabawi and de Lasa [10] for the combined 


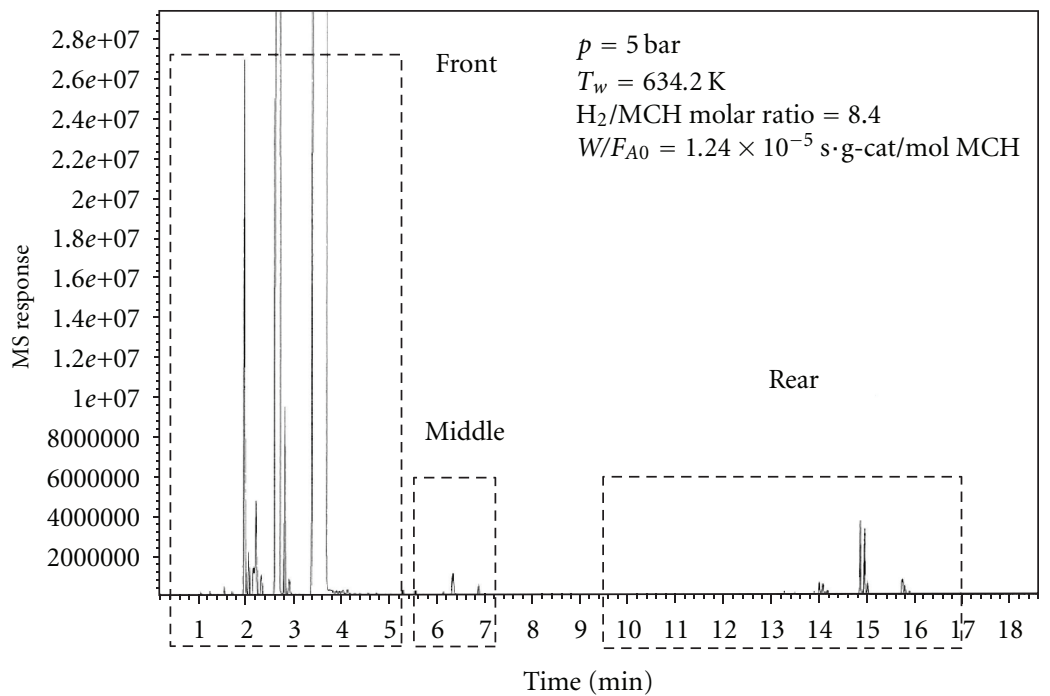

(a)

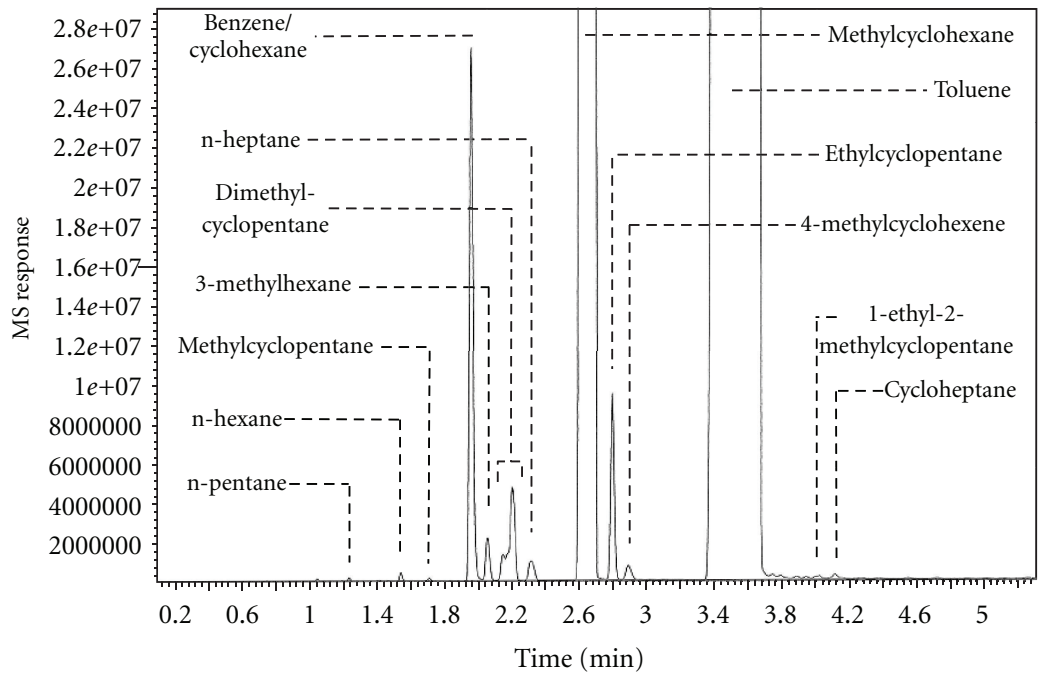

(b)

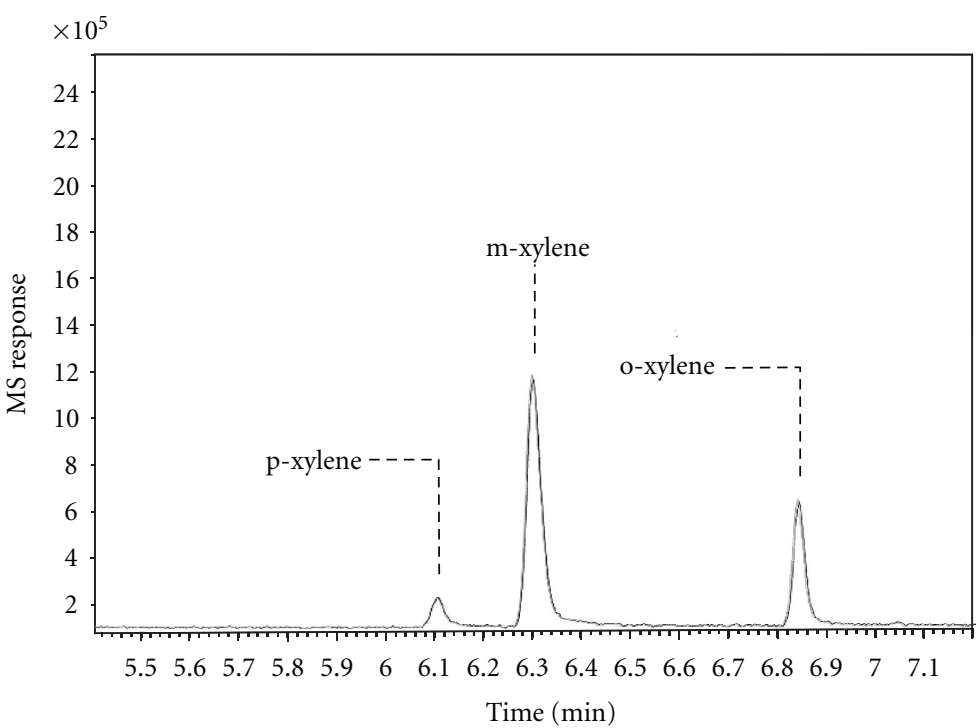

(c)

FIgUre 1: Continued. 


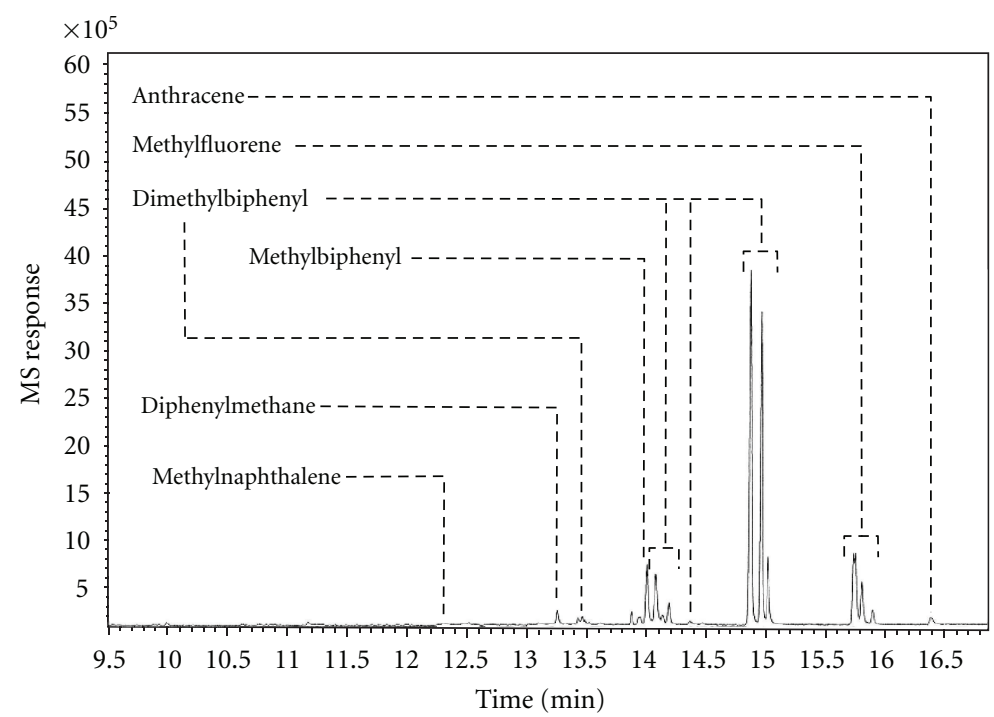

(d)

FIGURE 1: A typical GC-MS response of a reaction product showing formation of various by-products: (a) complete chromatogram, (b) front end of the chromatogram, (c) middle part of the chromatogram, (d) rear end of the chromatogram. GC-MS model-6890N from Agilent technologies with a nonpolar capillary column (50 m, HP-5 MS: 5\% phenyl and 95\% dimethylpolysiloxane).

Ethyl-

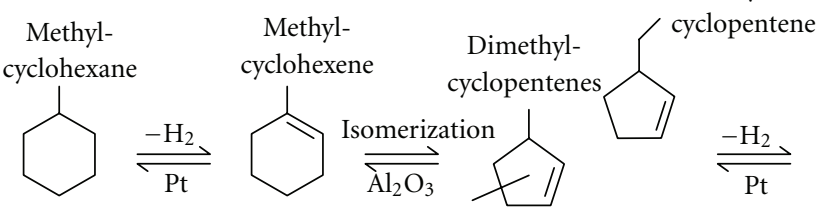

Dimethyl-

$\mathrm{Pt} \|+\mathrm{H}_{2}$ cyclopentanes<smiles>CCC(C)CC1CCCC1CC</smiles>

(a)<smiles>CC1C2CC3CC(C2)CC1C3</smiles>

Ethyl-

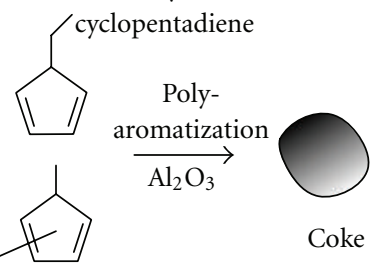

Dimethyl-

cyclopentadienes

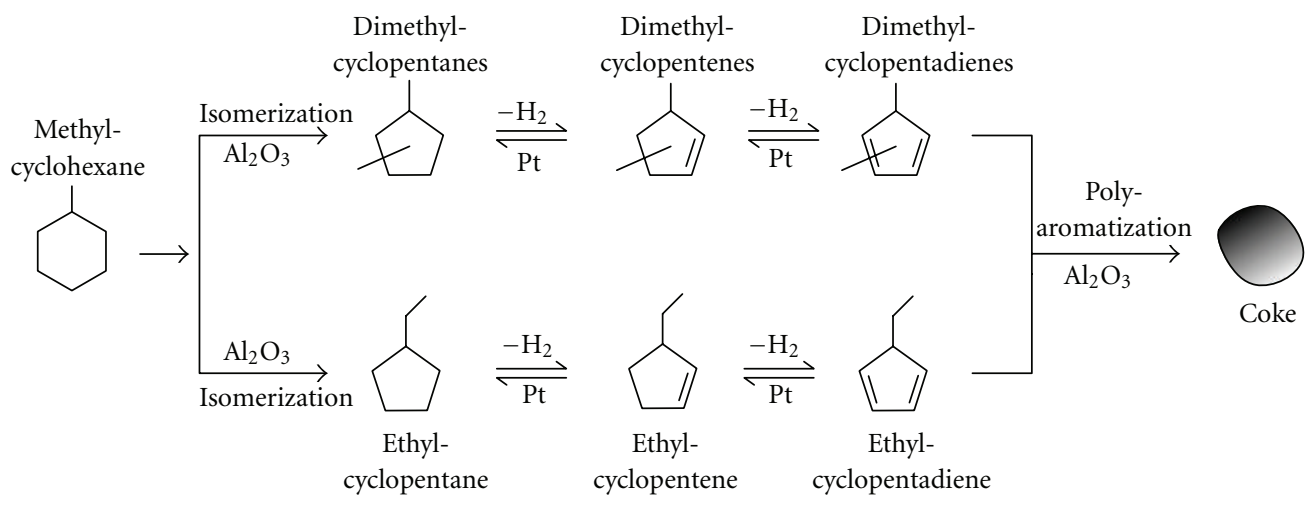

(b)

FIGURE 2: Mechanism for the formation of ring-closed products (RCPs): (a) Mechanism-I, (b) Mechanism-II. 


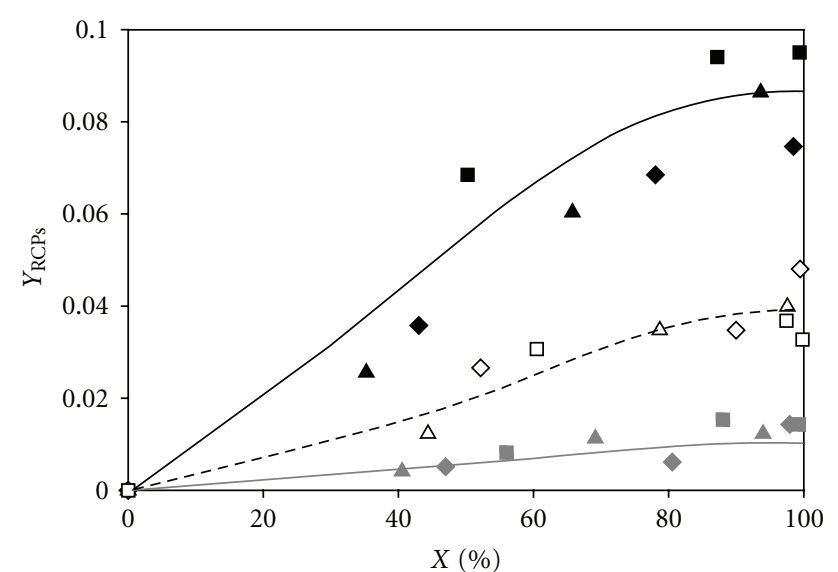
$\Delta$ Group-11, $T_{w}=614.2 \mathrm{~K}$
Group-11, $T_{w}=634.2 \mathrm{~K}$
- Group-11, $T_{w}=653.2 \mathrm{~K}$
$\triangle$ Group-31, $T_{w}=614.2 \mathrm{~K}$
$\diamond$ Group-31, $T_{w}=634.2 \mathrm{~K}$

(a)

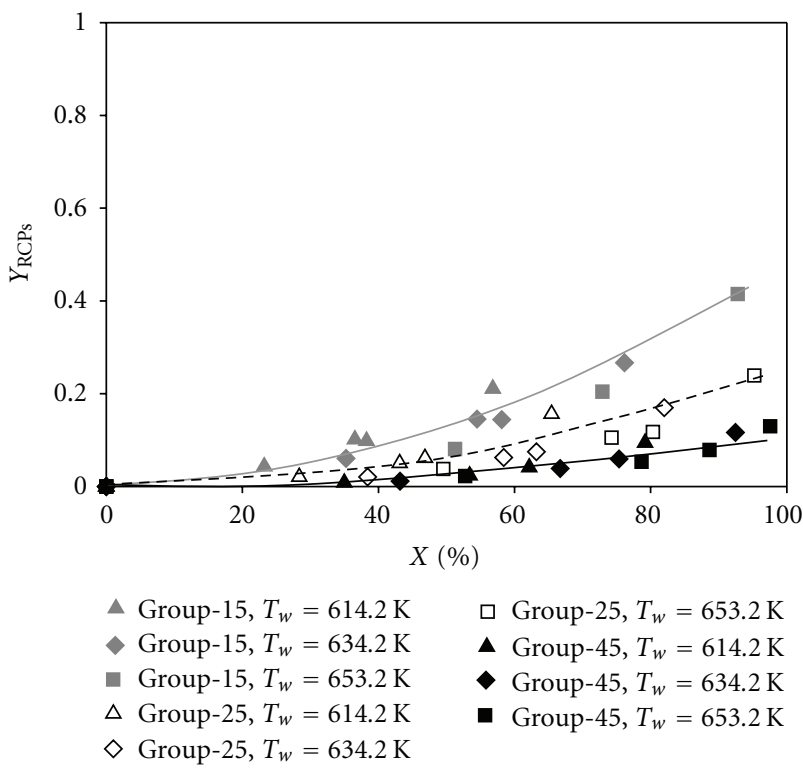

(b)

FIGURE 3: Effect of feed composition on the formation of ringclosed products (RCPs): (a) 1.013 bar and (b) 5.0 bar.

yields of ECP and DMCPs for cracking of MCH over FCC zeolite catalyst (acidic catalyst) at low pressures. Either of the two mechanisms shown in Figure 2 may be used to explain the phenomenon. For example, for the Mechanism-II, in the low conversion region, isomerization activity was observed to be dominant; however, as the reaction proceeded to completion, the naphthenes formed during the reaction started disappearing by dehydrogenating to cyclopentenes. Although cyclopentenes were not observed in the reaction products, their ultimate product (coke) was definitely observed on the catalyst surface. Figure 3 shows a comparison between

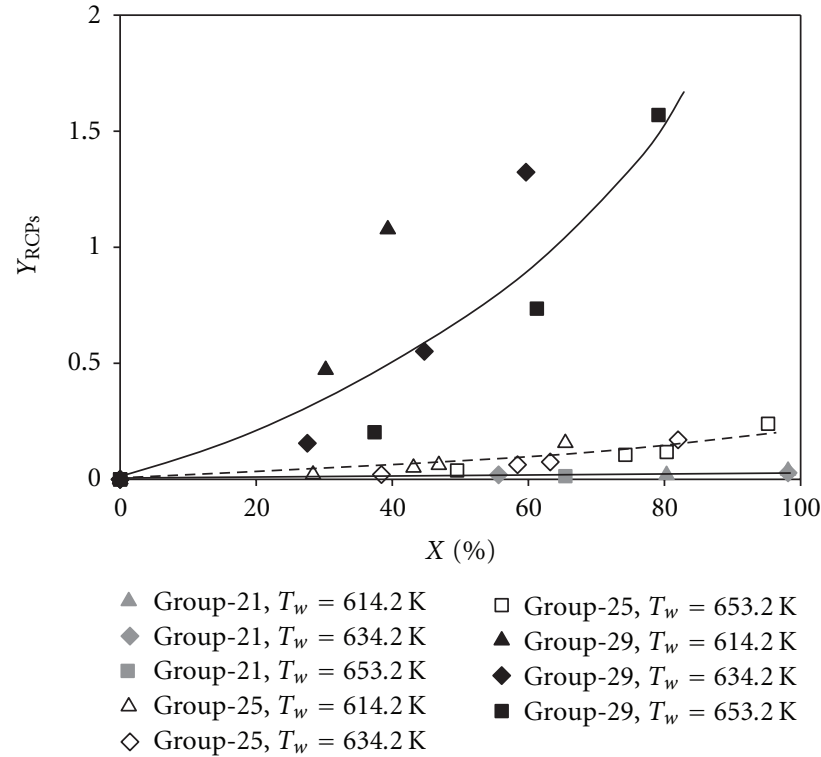

FIGURE 4: Effect of reactor pressure on the formation of ring-closed products (RCPs).

the effect of hydrogen concentration in the reaction mixture at low pressure (1.013 bar) and at high pressure ( 5 bar). It is observed that unlike at atmospheric pressure, the yield of RCPs is increased at high pressure with an increase in hydrogen concentration in the reaction mixture. Figure 4 shows the strong positive effect of pressure on the yields of RCPs especially in the relatively high pressure region. At high pressures, in contrast to $1.013 \mathrm{bar}$, the yield of RCPs increases continuously with an increase in the MCH conversion. At 9 bar pressure, the yield patterns are also found to be a function of temperature.

From the above discussion, it may be deduced that at low pressure, RCPs may be the reaction intermediates in a side reaction; however, at high pressures that side reaction is impeded and yield of RCPs increases continuously. Moreover, at high pressures, concentration of hydrogen in the reaction mixture is playing a definite role in decreasing the rate of disappearance of RCPs.

\subsection{Methylcyclohexenes (MCHes)}

3.2.1. Reaction Mechanism for the Formation of MCHes. In the literature $[5,11,12]$, the overall dehydrogenation reaction of $\mathrm{MCH}$ to toluene is suggested to comprise of successive dehydrogenation steps, as shown below:

$$
\begin{aligned}
\text { Methylcyclohexane } & \stackrel{-\mathrm{H}_{2}}{\rightleftharpoons} \text { Methylcyclohexene } \\
& \stackrel{-\mathrm{H}_{2}}{\rightleftharpoons} \text { Methylcyclohexadiene } \stackrel{-\mathrm{H}_{2}}{\rightleftharpoons} \text { Toluene }
\end{aligned}
$$

In the above reaction sequence, (2), methylcyclohexene $(\mathrm{MCHe})$ and methylcyclohexadiene (MCHde) are the reaction intermediates. The presence of $\mathrm{MCHe}$ in the reaction 


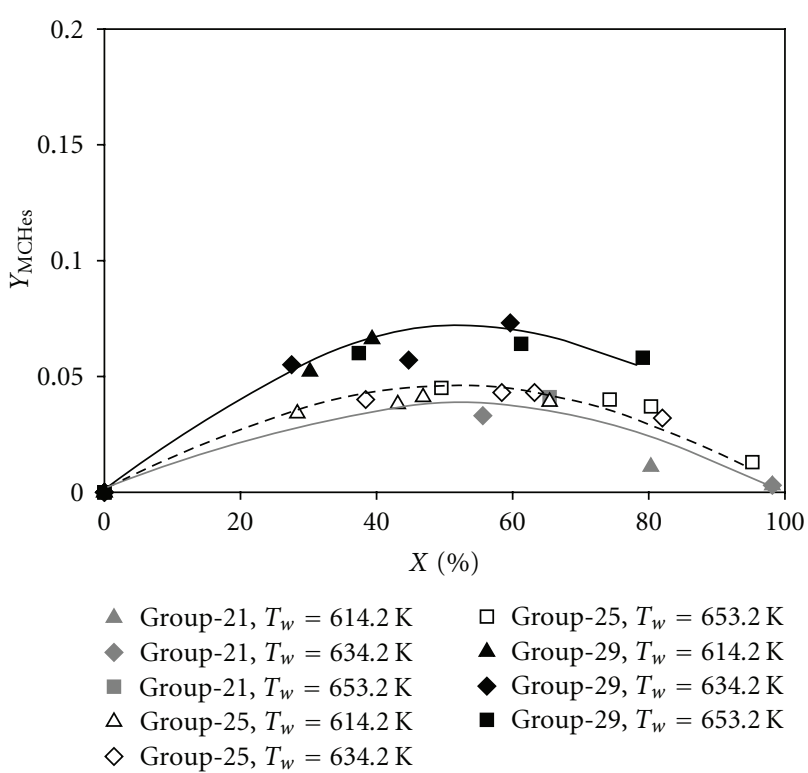

FIGURE 5: Effect of reactor pressure on the formation of methylcyclohexenes (MCHes).

products may suggest that the reaction follows the route given in the above sequence. Although in our study MCHde has never been found present in the dehydrogenated products, it cannot be stated that it is not formed once the reaction has started following the sequence given in (2).

3.2.2. Yield Patterns of MCHes. Figures 5 and 6 show the yields of MCHes formed under various groups of operating conditions. The yield of methylcyclohexenes is a combination of 1-MCHe and 4-MCHe. 3-MCHe has not been found and identified in the reaction products. Generally, the yield of MCHes first increases at low conversions; it reaches a maximum and then decreases at high conversions of $\mathrm{MCH}$ to toluene. This type of behavior may validate methylcyclohexene as a reaction intermediate in the dehydrogenation of methylcyclohexane to toluene. The maximum in the MCHes yield generally occurs around $50 \%$ of the $\mathrm{MCH}$ conversion. The yields of MCHes tend to approach zero at the complete conversion of $\mathrm{MCH}$. Figure 5 shows the effect of pressure upon the MCHes formation. It can be clearly seen that an enhanced yield of MCHes is the result at high pressures. This may be attributed to the reversible nature of the dehydrogenation reaction. The relative increase in the yields with pressure is observed to be higher at relatively high pressures.

Figure 6 shows the effect of feed composition on the $\mathrm{MCHe}$ formation and indicates that the concentration of hydrogen in the reaction mixture has a direct effect on the formation of MCHes. Again different behaviors are observed at 1.013 bar and 5 bar pressures. An increased conversion of MCHes with increase in the hydrogen concentration in the reaction mixture shows the increased rates of reversible reactions.

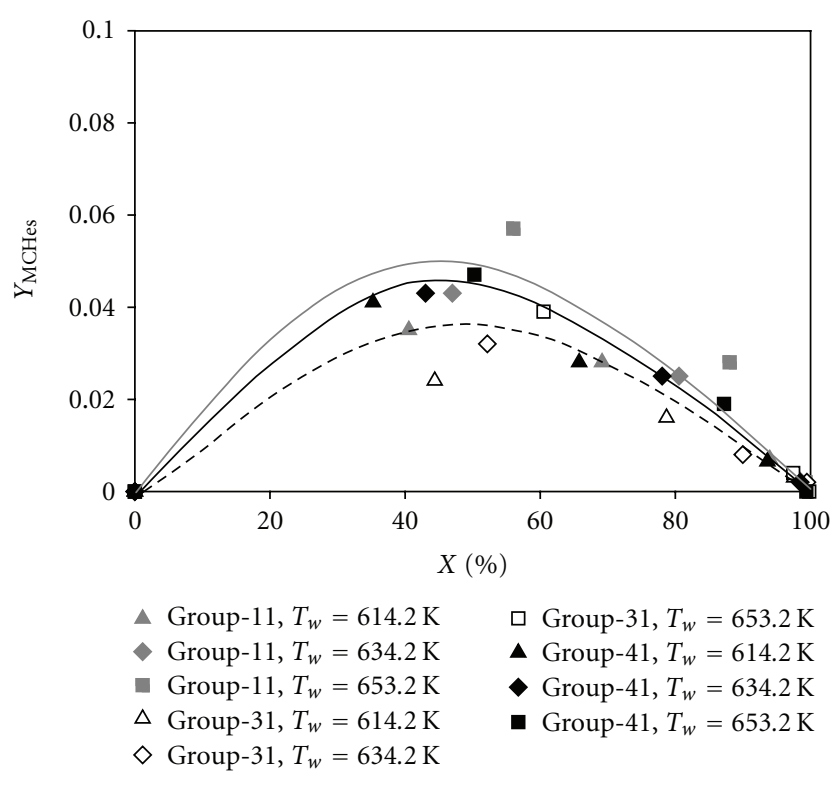

(a)

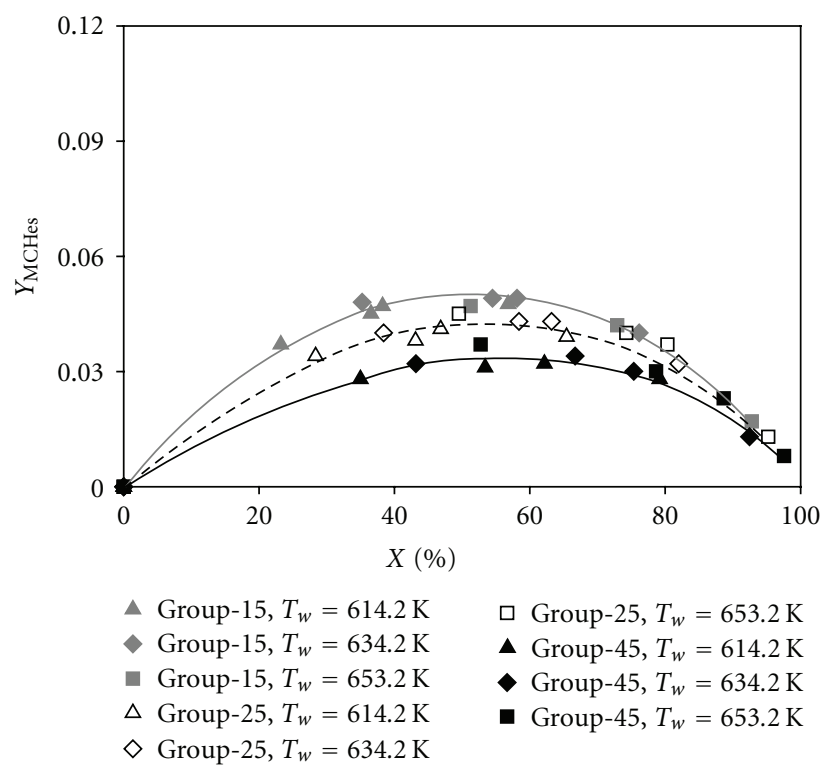

(b)

FIGURE 6: Effect of feed composition on the formation of methylcyclohexenes (MCHes): (a) 1.013 bar and (b) 5.0 bar.

\section{Conclusions}

The formation and yield patterns of ring-closed products (ethylcyclopentane and dimethylcyclopentanes) and methylcyclohexenes during the dehydrogenation of methylcyclohexane over $1.0 \mathrm{wt} \% \mathrm{Pt} / \gamma-\mathrm{Al}_{2} \mathrm{O}_{3}$ are studied. Generally, the yield of RCPs is observed to increase with an increase in the $\mathrm{MCH}$ conversion; while the yield of MCHes first increases at low conversions, it reaches a maximum and then decreases at high conversions of $\mathrm{MCH}$ to toluene. Both the yields of RCPs and MCHes were increased with an increase in the reactor pressure. The effect of hydrogen 
concentration in the reaction mixture has a separate role at low pressure (1.013 bar) and at high pressure ( 5 bar) for both the formation of RCPs and MCHes. At low pressure, it may be deduced that RCPs are the reaction intermediates in a certain side reaction. The yield patterns of MCHes may confirm methylcyclohexene as a reaction intermediate in the dehydrogenation of methylcyclohexane to toluene.

\section{Nomenclature}

$F_{A 0}$ : Initial molar flow rate of methylcyclohexane, $\mathrm{mol} / \mathrm{s}$

p: $\quad$ Reaction pressure, $\mathrm{Pa}$

$T_{w}$ : $\quad$ Reactor wall temperature, $\mathrm{K}$

$W: \quad$ Weight of catalyst, $\mathrm{kg}$

$X: \quad$ Methylcyclohexane conversion

$y_{A 0}$ : Initial mole fraction of methylcyclohexane

$y_{C 0}: \quad$ Initial mole fraction of hydrogen

$y_{I 0}: \quad$ Initial mole fraction of inerts

$Y_{\mathrm{MCHes}}$ : Yield of methylcyclohexenes, \%

$Y_{\mathrm{RCPs}}$ : Yield of ring closed products, \%.

\section{Acknowledgment}

M. R. Usman acknowledges the Higher Education Commission of Pakistan for funding the project.

\section{References}

[1] K. Jothimurugesan, S. Bhatla, and R. D. Srivastava, "Kinetics of dehydrogenation of methylcyclohexane over a platinumrhenium-alumina catalyst in the presence of added hydrogen," Industrial \& Engineering Chemistry Fundamentals, vol. 24, no. 4, pp. 433-438, 1985.

[2] F. S. Alhumaidan, Hydrogen storage in liquid organic hydrides: producing hydrogen catalytically from methylcyclohexane [Ph.D. thesis], The University of Manchester, Manchester, UK, 2008.

[3] M. R. Usman, "Catalytic dehydrogenation of methylcyclohexane over monometallic catalysts for on-board hydrogen storage, production, and utilization," Energy Sources A, vol. 33, pp. 2231-2238, 2011.

[4] M. R. Usman, D. L. Cresswell, and A. A. Garforth, "By-products formation in the dehydrogenation of methylcyclohexane," Petroleum Science and Technology, vol. 29, no. 21, pp. 2247-2257, 2011.

[5] M. Usman, D. Cresswell, and A. Garforth, "Detailed reaction kinetics for the dehydrogenation of methylcyclohexane over Pt catalyst," Industrial \& Engineering Chemistry Research, vol. 51, pp. 158-170, 2012.

[6] D. E. Tsakiris, Catalytic production of hydrogen from liquid organic hydride [Ph.D. thesis], The University of Manchester, Manchester, UK, 2007.

[7] J. H. Sinfelt and J. C. Rohrer, "Kinetics of the catalytic isomerization-dehydroisomerization of methylcyclopentane," Journal of Physical Chemistry, vol. 65, no. 6, pp. 978-981, 1961.

[8] V. Haensel, G. R. Donaldson, and F. J. Riedl, "Mechanisms of cyclohexane conversion over platinum-alumina catalysts," in Proceedings of the 3rd International Conference Catalysis, vol. 1, pp. 294-307, 1965.
[9] C. G. Myers, W. H. Lang, and P. B. Weisz, "Aging of platinum reforming catalysts," Industrial \& Engineering Chemistry Research, vol. 53, pp. 299-302, 1961.

[10] M. Al-Sabawi and H. de Lasa, "Kinetic modeling of catalytic conversion of methylcyclohexane over USY zeolites: adsorption and reaction phenomena," AIChE Journal, vol. 55, no. 6, pp. 1538-1558, 2009.

[11] J. H. Sinfelt, H. Hurwitz, and R. A. Shulman, "Kinetics of methylcyclohexane dehydrogenation over PT- $\mathrm{Al}_{2} \mathrm{O}_{3}$," Journal of Physical Chemistry, vol. 64, no. 10, pp. 1559-1562, 1960.

[12] P. A. Van Trimpont, G. B. Marin, and G. F. Froment, "Kinetics of methylcyclohexane dehydrogenation on sulfided commercial platinum/alumina and platinum-rhenium/alumina catalysts," Industrial and Engineering Chemistry Fundamentals, vol. 25, no. 4, pp. 544-553, 1986. 

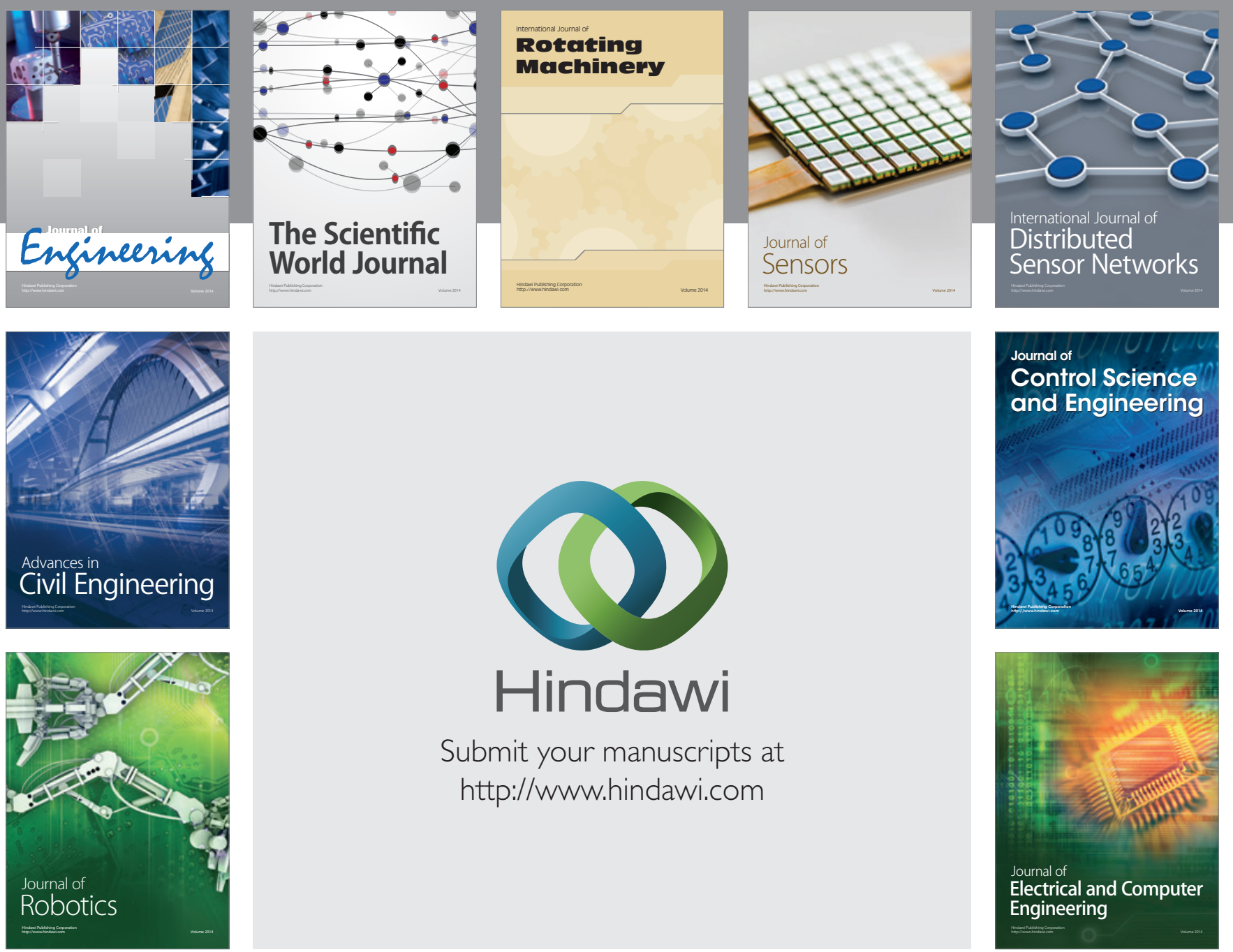

Submit your manuscripts at

http://www.hindawi.com
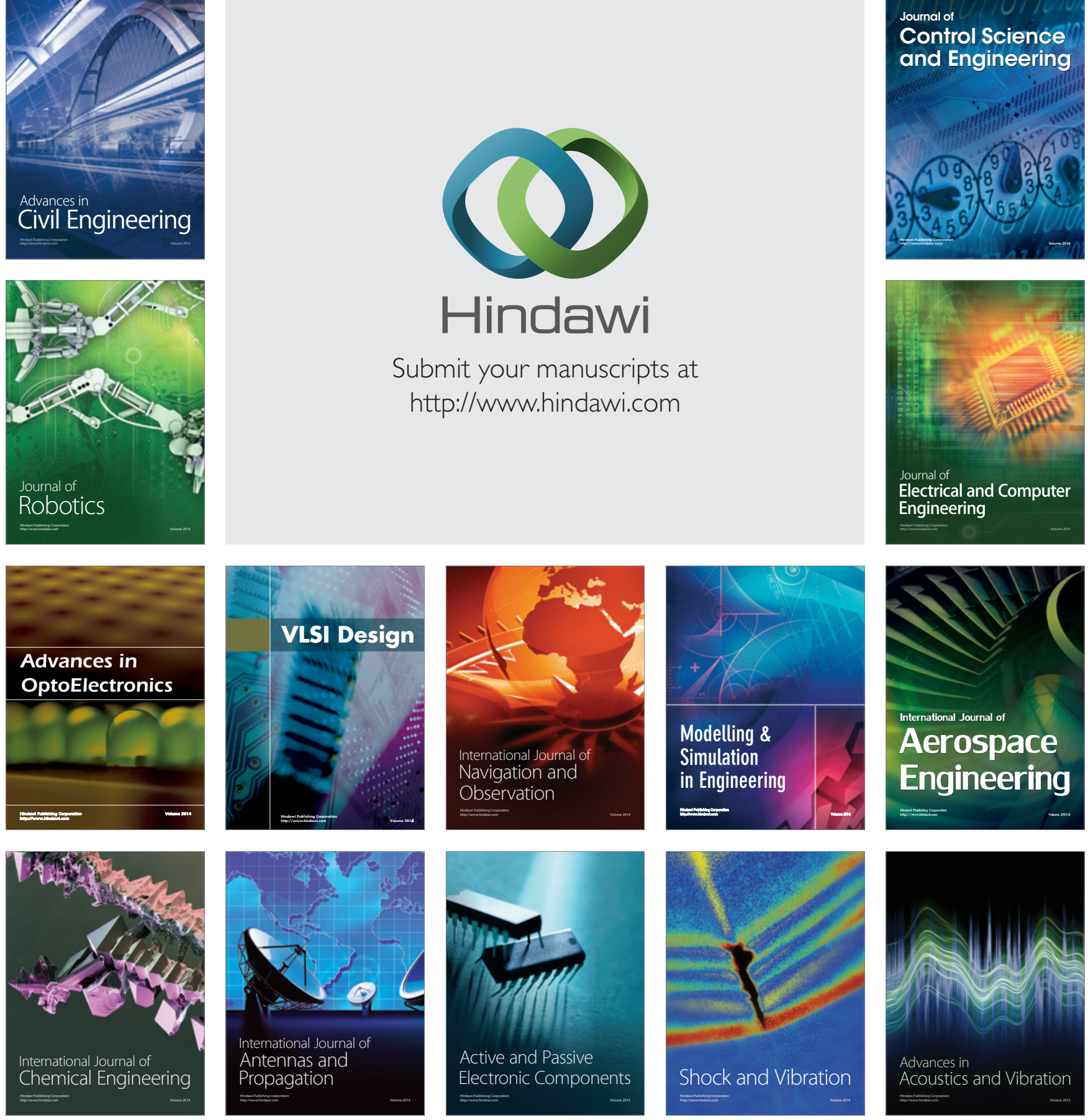